\title{
Author Correction: Lattice-confined Ru clusters with high CO tolerance and activity for
} the hydrogen oxidation reaction

Yuanyuan Zhou, Zhenyang Xie, Jinxia Jiang, Jian Wang, Xiaoyun Song, Qian He, Wei Ding (D) and Zidong Wei(D)

Correction to: Nature Catalysis https://doi.org/10.1038/s41929-020-0446-9, published online 27 April 2020.

In the version of this Article originally published, the label ' $\mathrm{H}_{2}: \mathrm{O}_{2}=10: 1$ ' in Fig. $5 \mathrm{c}$ and $\mathrm{d}$ was incorrect; it should have been ' $\mathrm{H}_{2}: \mathrm{CO}=10: 1$ '. In addition, the label ' $\mathrm{TiO}_{2}$ ' in Fig. 6a was incorrect; it should have been ' $\mathrm{Ru} / \mathrm{C}$ '. These errors have now been corrected.

Published online: 24 March 2021

https://doi.org/10.1038/s41929-021-00601-5

(C) The Author(s), under exclusive licence to Springer Nature Limited 2021 